\section{A case of Brunner's gland hyperplasia with features of duodenal cancer}

\author{
Keiichiro Kume, Masahiro Yamasaki, \\ Ryoichi Narita, Ichiro Yoshikawa \\ Third Department of Internal Medicine, \\ University of Occupational and \\ Environmental Health, Japan, School \\ of Medicine, Kitakyusyu, Japan
}

\begin{abstract}
A rare case of Brunner's gland hyperplasia mimicking duodenal cancer is reported. A 68year old woman had an elevated lesion in the second portion of the duodenum. Endoscopy after spraying with indigo carmine dye showed a granular appearance and fold convergence. The biopsy specimen suggested hyperplasia without malignancy. However, since the endoscopic features strongly suggested malignancy, endoscopic mucosal resection (EMR) was performed to establish the correct diagnosis. The final pathology diagnosis was Brunner's hyperplasia.
\end{abstract}

\section{Introduction}

Brunner's gland hyperplasia, also known as Brunneroma or polypoid hamartoma, is a rare, benign, proliferative lesion arising from the Brunner's glands of the duodenum; it accounts for $10.6 \%$ of benign tumors of the duodenum. Several cases of Brunner's gland hyperplasia causing hemorrhage, obstruction, or intussusception have been published in the adult literature. ${ }^{2}$ Similar cases in the pediatric population are very rare, and only 3 have been described. ${ }^{3}$ However, patients with Brunner's gland hyperplasia are usually asymptomatic and the lesions are discovered incidentally. ${ }^{1}$ It is easy to diagnose Brunner's gland hyperplasia on endoscopy. This article reports a case of Brunner's gland hyperplasia mimicking duodenal cancer.

\section{Case Report}

A 68-year old woman presented with hematemesis. Endoscopy revealed a bleeding ulcer with an exposed vessel on the anterior wall of the duodenal bulb. Endoscopic hemostasis was achieved with a hemostatic clip. Endoscopy performed seven days later demonstrated a healing ulcer in the bulb and an ele- vated lesion with a granular appearance and fold convergence in the second portion of the duodenum (Figure 1). Endoscopy after spraying with indigo carmine dye showed that the tumor surface was covered with irregular and granular gastric-like mucosa without a glandular pattern and fold convergence (Figure 2). Endoscopic ultrasonography revealed that the lesion was limited to the mucosal layer (Figure 3 ). The biopsy specimen suggested hyperplsia without malignancy. However, since the endoscopic features strongly suggested malignancy, endoscopic mucosal resection (EMR) was performed to establish the correct diagnosis. The resected specimen was $11 \times 10 \mathrm{~mm}$ in size, and histological examination revealed that the tumor was composed of Brunner's gland hyperplasia without malignancy (Figures 4 and 5). The final histological diagnosis was Brunner's hyperplasia.

\section{Discussion}

The cause of Brunner's gland hyperplasia is thought to be chronic inflammation, chronic stimulus by excessive secretion of gastric acids, or a decrease in pancreatic exocrine function. However, it has recently been thought that the hyperactivity of the exocrine modulating factor (hormone, vagus nerve and intestinal mucous membrane factor) is the major cause of Brunner's gland hyperplasia. ${ }^{4}$

In 1934, Feyrter classified the abnormal glandular proliferation into the following three types: diffuse hyperplasia (type 1), nodular hyperplasia (type 2), and adenomatous hyperplasia (type 3). ${ }^{5 \cdot 7}$ This nodular hyperplasia (type 2) is often mistaken for a malignancy. The diagnosis of Brunner's gland hyperplasia is supported by endoscopy and radiological findings. However, the sensitivity of endoscopy is $72-89 \%$ and occasionally, endoscopy is not useful in making the diagnosis. ${ }^{1,2,6,7}$

Endoscopic pinching biopsy usually gives a negative result, because the tumor is almost entirely covered with thick intact duodenal mucosa in the biopsy sites, and the biopsy is often not deep enough to reach the submucosal tumor tissue. ${ }^{8}$ Moreover, the present author previously reported gastric cancer mimicking submucosal tumor ${ }^{9}$ and angiodysplasia. ${ }^{10}$ Since a biopsy specimen taken from the former lesion did not show any histological features of malignancy, endoscopic mucosal resection (EMR) was performed to establish the correct diagnosis. Thus, since in the present case an endoscopic view of the tumor showed that it had a granular appearance and fold convergence, which suggested the possibility of carcinoma, EMR was performed. On the other hand, EMR appears to be a safe and efficient method for management of intramucosal carcinoma of
Correspondence: Keiichiro Kume,

The Third Department of Internal Medicine, University of Occupational and Environmental Health, Japan, School of Medicine, 1-1, Iseigaoka, Yahatanishi-ku, Kitakyusyu 807-8555, Japan

E-mail: k-kume@med.uoeh-u.ac.jp

Key words: Brunner's gland, duodenal cancer.

Received for publication: 10 August 2009. Revision received: 30 October 2009. Accepted for publication: 12 November 2009.

This work is licensed under a Creative Commons Attribution 3.0 License (by-nc 3.0)

CCCopyright K. Kume, et al., 2009

Licensee PAGEPress, Italy

Gastroenterology Insights 2009; 1:e8

doi:10.4081/gi.2009.e8

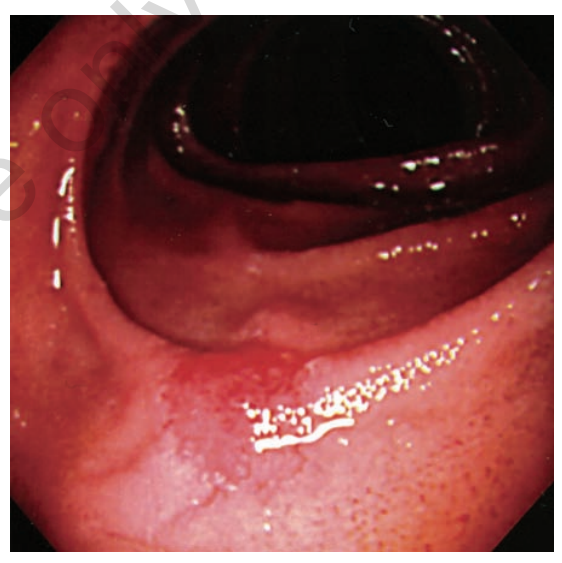

Figure 1. Endoscopy reveals an elevated lesion with a granular appearance and fold convergence in the second portion of the duodenum.

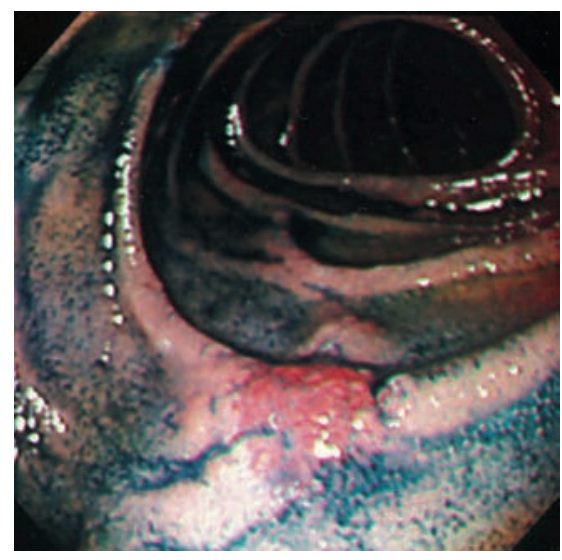

Figure 2. Endoscopy after spraying with indigo carmine dye shows that the tumor surface is covered with irregular and granular gastric-like mucosa without glandular pattern and fold convergence. 


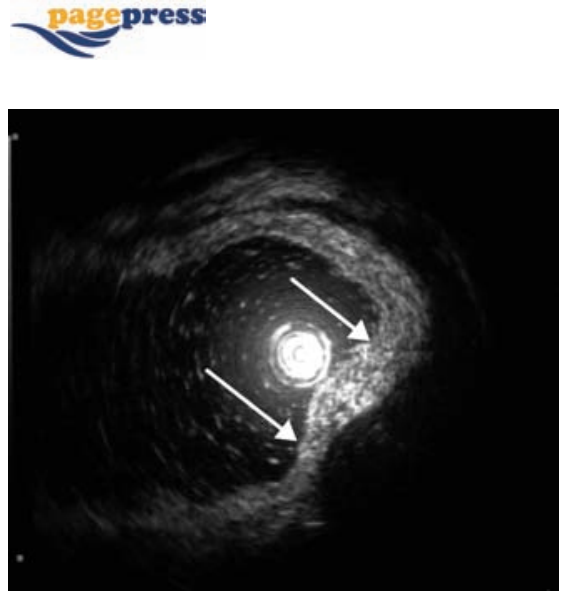

Figure 3. Endoscopic ultrasound reveals that the lesion is limited to the mucosal layer (arrows).

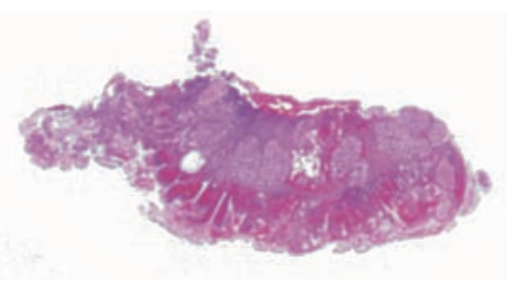

Figure 4. A loupe image of the resected specimen $(H \& E$, original magnification $X$ 4).

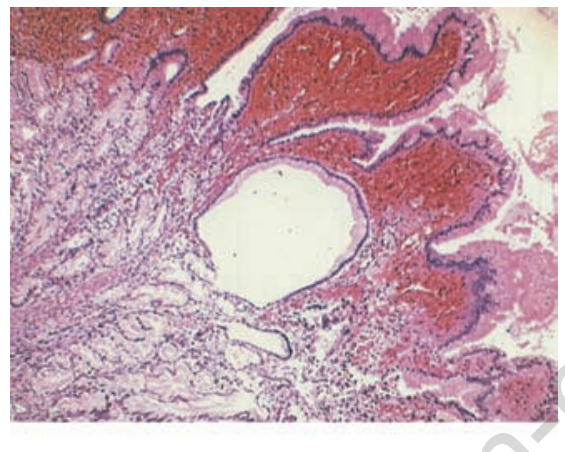

Figure 5. Histological examination shows that the tumor is composed of Brunner's gland hyperplasia without malignancy $(\mathbf{H}$ \&E, original magnification $\mathrm{X} 80$ ). the duodenum, as well as in the other regions of the gastrointestinal tract. ${ }^{11}$

It is still controversial whether asymptomatic Brunner's gland hyperplasia or adenoma found incidentally needs surgical removal. Some people think that it needs no treatment, whereas others believe it should undergo endoscopic excision in order to prevent complications. There have been several reports ${ }^{12,13}$ that Brunner's gland hyperplasia or adenoma could give rise to acute profuse bleeding which results in shock. On the other hand, it has been reported that a pedunculated polyp with carcinoma is thought to have developed due to induction of gastric-foveolar differentiation in a manner very similar to that of gastric metaplasia in hyperplastic Brunner's glands. ${ }^{14}$

In conclusion, although Brunner's gland hyperplasia mimicking duodenal cancer is very rare, it should be taken into consideration in the differential diagnosis of duodenal cancer. Furthermore, it is important to perform EMR to establish the correct diagnosis.

\section{References}

1. Iusco D, Roncoroni L, Violi V, Donadei E, Sarli L. Brunner's gland hamartoma: 'overtreatment' of a voluminous mass simulating a malignancy of the pancreatic-duodenal area. JOP 2005;6:348-53.

2. de Silva S, Chandrasoma P. Giant duodenal hamartoma consisting mainly of Brunner's glands. Am J Surg 1977;133:2403.

3. El Faleh I, Lutz N, Osterheld MC, Reinberg 0 , Nydegger A. Gastric outlet obstruction by Brunner's gland hyperplasia in an 8year-old child. J Pediatr Surg 2009;44:E214.

4. Franzin G, Musola R, Ghidini 0, Manfrini C, Fratton A. Nodular hyperplasia of Brunner's glands. Gastrointest Endosc
1985;31:374-8.

5. Feyrter F. Wucherungen BD. Über Wucherungen der Brunnerschen. Drüsen. Virchows Arch (Pathol Anat) 1934;293: 509-26.

6. Gourtsoyiannis NC, Bays D, Papaioannou $\mathrm{N}$, Theotokas J, Barouxis G, Karabelas T. Benign tumors of the small intestine: preoperative evaluation with a barium infusion technique. Eur J Radiol 1993;16:11525.

7. Cwikiel W, Andren-Sandberg A. Diagnostic difficulties with duodenal malignancies revisited: a new strategy. Gastrointest Radiol 1991;16:301-4.

8. Gourtsoyiannis NC, Zarifi M, Gallis P, Mouchtouris A, Livaditou A. Radiologic appearances of Brunner's gland adenoma: a case report. Eur J Radiol 1990;11:188-90.

9. Kume K, Yoshikawa I, Yamasaki M, Abe S, Murata I, Otsuki M. A case of gastric cancer with features of submucosal tumor. Gastrointest Endosc. 2001:53;247-9.

10. Kume K, Yoshikawa I, Myojo T, Otsuki M. Gastric cancer mimicking angiodysplasia. Endoscopy. 2004;36:376.

11. Kume K, Okubo Y, Ejiri Y, Abe S, Hakozaki H, Murata I, Yoshikawa I, Otsuki M. Early duodenal carcinoma successfully treated by endoscopic mucosal resection. Dig Endosc. 2000:12;177-80.

12. Peetz ME, Moseley HS. Brunner's gland hyperplasia. Am Surg1989;55:474-7.

13. Levine JA, Burgart LJ, Batts KP, Wang KK. Brunner's gland hamartomas: clinical presentation and pathological features of 27 cases. Am J Gastroenterol 1995;90:2904.

14. Kushima R, Stolte M, Dirks K, Vieth M, Okabe H, Borchard F, Hattori T. Gastrictype adenocarcinoma of the duodenal second portion histogenetically associated with hyperplasia and gastric-foveolar metaplasia of Brunner's glands. Virchows Arch 2002;440:655-9. 